UNIVERSIDAD DEL CEMA

Buenos Aires

Argentina

Serie

DOCUMENTOS DE TRABAJO

\author{
Área: Economía \\ UNDERSTANDING REPUGNANCE: \\ IMPLICATIONS FOR PUBLIC POLICY
}

Julio Elias, Nicola Lacetera y Mario Macis

Agosto 2017

Nro. 614

www.cema.edu.ar/publicaciones/doc_trabajo.html

UCEMA: Av. Córdoba 374, C1054AAP Buenos Aires, Argentina

ISSN 1668-4575 (impreso), ISSN 1668-4583 (en línea)

Editor: Jorge M. Streb; asistente editorial: Valeria Dowding <jae@cema.edu.ar> 



\title{
Understanding Repugnance: Implications for Public Policy 1
}

\author{
Julio Elias (Universidad del CEMA) \\ Nicola Lacetera (University of Toronto) \\ Mario Macis (Johns Hopkins University) ${ }^{2}$
}

\begin{abstract}
Understanding the influence of moral repugnance on social decisions is challenging, particularly because in several cases not all of the relevant policy options can be observed. In a series of recent studies, we designed survey experiments to identify individual preferences in morally controversial transactions, with focus on the provision of payments to kidney donors in the United States (Elias, Lacetera and Macis 2015a-b, 2016a). We found that providing information on how a price mechanism can help alleviate the organ shortage significantly reduces opposition toward payments for organs. Moreover, we quantified the trade-off that people make between the repugnance and the efficiency of alternative kidney procurement systems. In Elias, Lacetera, Macis and Salardi (2017), finally, we analyzed how the regulation of controversial activities is related to economic development. This paper summarizes these findings and analyzes their main implications for public policy and market design.
\end{abstract}

\footnotetext{
${ }^{1}$ This paper is based on Elias, Lacetera and Macis (2015a, 2015b, 2016a, 2016b) and Elias, Lacetera, Macis and Salardi (2017). The views of the authors do not necessarily represent the views of the universities they are affiliated to.

${ }^{2}$ Emails: je49@ucema.edu.ar; nicola.lacetera@utoronto.ca; mmacis@jhu.edu, respectively.
} 


\section{Introduction}

In most modern societies, several transactions are prohibited or restricted. In addition to reasons related to health, safety or negative externalities, the motivation for banning certain trades resides mainly in ethical concerns - in other words, societies perceive these transactions as "repugnant". Roth (2007) introduced in the economics literature the concept of "repugnance" for a transaction as the aversion toward other individuals engaging in it, even if the parties directly involved benefit from that trade (i.e. "There are some things no one should be allowed to do"). Repugnance considerations have important consequences on the types of markets and transactions that we observe and, as such, they impose a challenge for policy and market design. This paper discusses recent experimental evidence on repugnance and its main implications, with specific reference to the procurement and allocation of kidneys for transplantation.

The United States as well as several other countries allow some forms of "trades" in the kidney market, specifically in the form of "kidney exchanges", whereby pairs of living would-be donors and recipients who prove incompatible look for another pair or pairs of donors and recipients who would be compatible for transplants, cutting their wait time. However, monetary compensation to people who give their organs are prohibited everywhere (with the exception of the Islamic Republic of Iran), because this is considered morally unacceptable.

The current policy debate on using markets to boost donations relies mainly on ethical arguments. One set of objections is based on concerns of exploitation of the poor and coercion of choice. In a recent debate in the New York Times, ethicist Katrina Bramstedt argues that allowing kidney sales would create "an economic class war." Another set of objections concerns the concept of human dignity that payments would hamper (Gillespie 2017); scholars have appealed to "inalienable values" and "fundamental truths" in opposing payments, (Delmonico et al. 2002), arguing that they would be "degrading the human condition" (Sandel 2012). The definitive words often used suggest that keeping these transactions out of the marketplace is considered a "protected value" -i.e., a value that people are unwilling to trade off no matter what the costs of doing so may be. In fact, arguments against payments for organs often acknowledge the potential benefits of allowing such trades; yet the moral basis of the opposition is considered strong enough to forego those benefits (Delmonico et al. 2002; Sandel 2012).

Understanding and quantifying the influence of repugnance on social decisions is challenging. For example, in the context of kidney donations we cannot observe a paid-donor regime because payments are illegal. In a series of recent papers (Elias, Lacetera and Macis 2015a, 2015b, and 2016a), we used survey experiments conducted in on-line platforms with US residents to study preferences for repugnance in morally controversial transactions, with focus on the provision of payments to kidney donors.

In a first study (ELM, 2015a), we found that providing information on how a price mechanism can help alleviate the organ shortage significantly reduced repugnance toward payments for organs. To further understand the effect of information, in ELM (2015b) we found no effect of general information about "market efficiency" on the support for paying organ donors. This indicates that the results of ELM (2015a) were not due to the participants' belief that markets 
can solve every social problem; rather, morally controversial economic incentives may be accepted only when they are seen as a solution to a specific problem.

In a more recent study (ELM, 2016a), we found that although systems that allow for payments to donors raise higher moral concerns than a system with no payments, a majority of individuals would be willing to accept a more repugnant system provided that it produced a sufficiently large additional number of transplants.

From a normative standpoint, there is disagreement as of what criteria should shape public policy and regulations and whether the preferences of the public should influence the design of those policies. For example, Gillespie (2017) claims that ethics and legality should be the main guide for policy design. In contrast, Brennan and Jaworski (2015) advance a consequentialist view to favor monetary transactions as long as this principle applies: "if you may do it for free, you may do it for money." Our evidence suggests that individuals care both about both "outcomes" (number of organs transplanted) and "process" (how those transplants were achieved), and balance the two when deciding what kind of system society should adopt. Our research thus suggests that individual choices based on repugnance considerations respond in a predictable way to efficiency, and to information and evidence about the likely effects of introducing incentives. As such, supplying evidence and promoting studies on organ donor payments and other morally sensitive topics might therefore lead to greater awareness and improved market design based on the actual preferences of a population. In the case of introducing regulated payments for organ donors and their families in particular, the evidence is that informing society about the potential benefits of economic incentives can substantially impact the acceptability of this transaction.

In the next two sections, we discuss in more detail the evidence that individuals consider both moral arguments and market efficiency when forming an idea about how a transaction should be regulated, and are willing to make trade-offs between morality and efficiency. In Sections 4 and 5 , we discuss evidence on how information and economic development could affect the regulation of morally contentious markets. We then conclude by discussing implications for public policy and market design.

\section{Repugnance can be Costly}

In order to identify and analyze moral repugnance from a public policy perspective it is important to define it first, since the term repugnance could have different meanings. Leider and Roth (2010) provide a useful definition: "We use repugnant in its economic sense-in a repugnant transaction the participants are willing to transact, but third parties disapprove and wish to prevent the transaction (rather than in its psychological sense of eliciting disgust among potential participants). Hence repugnant transactions are often illegal."

If the repugnance only directly affected people's wellbeing, then the only source of tension over regulations and market design would be people's disagreement. Some groups of individuals may enjoy engaging in a repugnant activity, and others may find it distasteful and 
would like to make it illegal. In this case, the net social cost of repugnance would depend on the magnitude of the disagreement (Elias 2017).

However, in most cases prohibiting a transaction on moral grounds can bear additional consequences. Each year in the U.S., for example, approximately 35,000 new patients require a kidney transplant, but only about 17,000 obtain one (Held et al. 2016). Recent estimates (Held et al, 2016) indicate that each additional transplant leads to about $\$ 200,000$ in direct savings; the social benefits rise to $\$ 1.1$ million per kidney recipient if we add the value of the increased life expectancy and quality. The total cost of the kidney shortage in the U.S. is estimated to be about $\$ 20$ billion annually.

Scholars and practitioners have discussed the introduction of monetary incentives to donors; Becker and Elias (2007), for example, estimate that payments between $\$ 15,000$ and $\$ 30,000$ would eliminate the waiting list in a few years. In fact, even those scholars and practitioners who oppose payment acknowledge that payments may enhance the supply of organs; however they consider the moral aversion to be a higher-order principle (Delmonico et al. 2002). Thus, the moral arguments to substantiate the prohibition of payments seem to be worth the costs deriving from a greater supply shortage.

Both the prediction that payments would increase supply and the concern for the moral consequences of paying donors are shared by the broader population, according to some findings that we report in ELM (2016a). In an auxiliary survey, respondents predicted the supply effects of, and expressed their moral concerns about ten possible kidney procurement and allocation systems; the systems differed in the way organs are procured (by a public agency, private system) and allocated to recipients (priority rules, private transactions, paired exchange), and in whether and how donors are remunerated (altruistic donation, heroes medal, paid donation: $\$ 20,000$ in cash, $\$ 20,000$ in kind). We also asked the respondents to predict the number of kidneys that each of the ten systems would produce.

Subjects predicted that systems that contemplated payments to donors would produce more kidney for transplants, but they also raised stronger moral concerns about these systems. Within payment-based systems, the identity of the payer (public agency versus recipient through a private transaction) was the strongest predictor of repugnance ratings. Systems with non-cash payments (such as a priority in the waitlist, symbolic medals, as well as kidney exchanges) were perceived as less efficient and had low repugnance ratings, similar to the unpaid donor regime. The "free market" system (i.e., a system of private transactions where recipients pay donors directly) had very high repugnance ratings but was not perceived as the one lading to the highest number of transplants. Thus according to these data, summarized in Figure 1, the respondents perceived an inverted U-shaped relationship between efficiency and repugnance. More repugnant systems were perceived to be more "productive", but only up to a point. Therefore, although some studies showed that a free market system would achieve the highest level of supply, people do not perceive it in that way. This evidence is particularly important for information-based policies that we discuss in section 4 . 


\section{The trade-offs between Repugnance and Supply effects}

The evidence on the relationship between supply effects and repugnance provides guidance on the "technical" or perceived relationship by the public. In this section, we discuss the main results of ELM (2016a) on individual preferences for efficiency and repugnance. ${ }^{3}$ The main questions are whether individuals care about repugnance and the supply effects of payments, and whether there are finite increases in the supply of kidneys for transplants generated by payments that would lead individuals to express a preference for a paid-donor system versus an unpaid-donor alternative, even if payments were considered more repugnant.

The analysis of potential tradeoffs between ethical and "material" effects of an activity is common to other streams of literature, for example to the study of whether people are more likely to engage in unethical behavior in exchange for economic rewards. Some insights on how individuals perceive certain moral values come from the literature on unethical conduct. There is evidence for example that subjects are willing to trade off moral concerns for personal financial or social gain. Gneezy (2005) finds that individuals are lie in exchange for personal financial gain, but that they also care about how other people are affected by their lies; Gibson et al. (2013) find evidence that individuals balance "process" against "consequences" when deciding whether to lie or not. It is not immediate, however, to extend this results to understanding whether people would support legalizing payments for organs in "exchange" of increases in organ supply. For example, even though an individual who is willing to sell a kidney for money is perhaps likely (but not necessarily) in favor of a law that allows payments, the converse is not true: people who are not willing to sell a kidney may or may not be willing to approve legislation that allows other to do it

In order to study preferences over the repugnance and supply effects of payments to kidney donors, in ELM (2016a) we conducted an choice experiment with about three thousand U.S. residents recruited through Amazon Mechanical Turk (mTurk henceforth). ${ }^{4}$ A potential concern of using mTurk workers is about the reliability and representativeness of our samples. We follow Kuziemko et al. (2015) in the analysis of the costs and benefit of relying on mTurk participants, and also note that most of our analysis considers differences rather than absolute values (e.g. in the preferences or approval rates of a system). The studies that we performed are more concerned on identifying and understanding different effects and mechanisms that are hard to measure using random assignment (internal validity) than to generalize the results to the population (external validity). The growing reliance on mTurk in several studies in economics suggests that more researchers recognize, on the balance, that benefits overcome the costs in several cases. We followed some increasingly established practices to allay concerns about the use of mTurk samples. For instance, we imposed restrictions to participation: first, the subjects had to be U.S. residents (Amazon records the respondents' home address, and mTurk defines a filter based on that); second, to exclude robots, we restricted participation to respondents with a past approval rate of at least $80 \%$; a high

\footnotetext{
${ }^{3}$ The results from this study as well as from some of the others mentioned below are in part also discussed in Lacetera (2017)

4 Amazon Mechanical Turk is an online platform where people can sign up as "workers" to perform tasks in exchange for monetary compensation. The platform has also become a popular source of experimental data for social scientists. See Buhrmester et al. (2011) and Mason and Suri (2012).
} 
approval rate is an indication that a participants had been taking their task on the platform with care and attention.

After providing an overview of the state of organ procurement and allocation in the United States, we asked the participants to consider three alternative organ procurement and allocation systems to increase living undirected kidney donations:

a. A system based on unpaid donors with allocation based on priority rules determined by the patients' medical situation, age, time on the waiting list, etc. (i.e., rules similar to those of the system currently used to allocate organs from deceased donors).

b. A system where donors would receive $\$ 20,000$ from a public agency, with allocation based on the same priority algorithm as the unpaid-donor system.

c. A system of individual, private transactions, where donors would receive $\$ 20,000$ from the organ recipient (out of pocket or through privately purchased insurance, for example).

After receiving this information, respondents expressed their opinion, through a rating system, about features of these three systems related to their moral repugnance in terms of six ethics features: coercion of choice (i.e., violation of autonomy), exploitation of the poor, unfairness for donor and recipient, human dignity, and accordance with a person's broad moral values. Our survey thus encompassed the key ethical concerns with autonomy and justice, two "guiding principles" of bioethics (Beauchamp and Childress 2013). We also included the concern for the respect of human dignity, because this principle is often a major argument against organ sales (Gillespie 2017; Radin 1987). Finally, the "consistent with your values" category was meant to give the subjects an opportunity to express their overall morality judgement, possibly including aspects not captured by our survey ${ }^{5}$

Finally, we asked the participants to assume that each system would result in a given efficiency in terms of the number of kidneys for transplantation procured, and to indicate their preferred system. The supply levels were randomly determined, and each participant had three choice opportunities, in a sequential manner.

Individuals, for the most part, did not express moral concerns about this system. The two paiddonor systems received, in general, higher repugnance ratings than the unpaid-donor system. However, there was a large difference according to whether the system contemplated payments by a public agency or by the recipients in private transactions, with the latter resulting as the most repugnant system.

Looking at choices, the likelihood of choosing a particular combination of repugnance and efficiency increased with the level of efficiency and decreased with repugnance. Respondents thus preferred options with higher efficiency and those considered less repugnant, but also

\footnotetext{
${ }^{5}$ Taken together, these concerns encompass a broad set of moral themes, because they include considerations about individual freedom (coercion and exploitation), the safeguard of societies (fairness and dignity), as well as principles related to the ultimate sacred nature of the human body (dignity).

Following the typology of Richard Shweder and his coauthors (Shweder et al. 1997), the moral arguments against payments for body fluids and parts refer to all three ethics of autonomy, community and divinity. Future work should try to integrate these principles, as well as other moral foundations, in the analysis.
} 
acknowledged, through their choices, a general trade-off between these two characteristics of the system.

Respondents also showed heterogeneous preferences. The majority made choices consistent with a consequentialist view that placed weight on supply enhancement and not only on ethical concerns, but there was a share of "deontological" subjects who were not willing to allow payments, irrespective of the expected number of lives saved. Whether an individual was closer to having consequentialist or deontological views was not related to sociodemographic characteristics, but was associated to broader attitudes as measured by a set of moral dilemmas typically used in moral psychology. Because we could not easily proxy preferences for morality versus efficiency with socio-demographic traits, we conclude that ethical views in these choices are central and cannot be neglected when designing market regulations.

One potential concern with our experimental design is that it artificially makes moral considerations (and efficiency) salient, since it explicitly asks participants to consider ethical issues. However, for repugnant transactions whose prohibition involves a high cost to society the arguments for this this prohibition are of ethical nature (see section 1), while also including efficiency considerations; in fact, our evidence suggests that the public does care about both the moral aspects and the supply effects of payments. In fact, if individuals feel strongly about the ethical aspects of a transactions, they may extend these considerations also to other morally controversially transactions. In the next section, for example, we will present evidence that, when thinking about legalizing prostitution, women reconsider their attitudes toward paying for organs and become more opposed to it. This association is present in the ethics literature; both paying for organs and for sex have been tied to the concept of "market inalienability" and considered against human dignity (Gillespie, 2017).

\section{Choices Can Change: The Role of Information}

A crucial question is whether repugnance, and the support for a certain transaction, can change over time or whether they reflect deeply held and hard-to-change values. Moral beliefs typically evolve slowly (Guiso, Sapienza and Zingales 2009); however, technological progress and the increased availability of data and research methods to measure the efficiency of certain transactions with greater accuracy might lead to more rapid changes in attitudes about their acceptability in response to changes in their costs and benefits.

The evidence of the previous sections is consistent with individuals reacting in a predictable way to changes in the technical relationship between repugnance and efficiency (i.e., the "efficiency-repugnance frontier"). Empirical evidence and scientific research on ways to increase the supply of human organs for transplantation (or the cost of prohibiting such methods) could affect people's perception of the frontier and, as a consequence, their system choice.

To assess the effect of information on the stated support for payments for human organs, in ELM (2015a) we conducted an online survey experiment with approximately 3,500 respondents residing in the United States and again recruited through mTurk. 
The participants were randomly assigned to different experimental conditions. The subjects in the treatment group received a short reading describing the current state of organ shortage in the United States and its consequences in terms of human lives lost, long wait lists, and financial costs. The text then reported on a few different strategies that have been proposed (and in some cases implemented) to alleviate the shortage, including kidney exchanges, changing the default rule for cadaveric organ donation, as well as regulated payments to donors or their families, with references to the academic studies that have evaluated these proposals. Finally, the subjects completed survey questions; the first of these questions involved reporting their opinions about whether they would favor the implementation of regulated payments for organ donors or their families. The control group received a placebo text, and was asked about their support for payments for organs.

Comparing the two groups, we found that, when given verifiable information and considerations about the organ shortage and potential ways to solve this problem, including the potential benefits of payments to organ donors, the share of individuals showing support for a market-based solution increased substantially, from $52 \%$ to $72 \%$. The overall effect of information was not driven by any specific sub-group of respondents For example, women and men had similar baseline levels of support and similar responses to information; liberals and moderates were only slightly more sensitive to information than were conservatives.

These findings raise additional questions to fully understand the mechanisms through which information affects attitudes about the acceptance of certain market transactions. A first question is whether providing general information on the welfare properties of prices and markets modify attitudes toward repugnant trades. It has been argued that stimulating a market-oriented approach in people may lead to a relaxation or even corruption of their moral values (see, for example, Sandel, 2012).

A second question is whether having additional knowledge on the benefits of using a price mechanism in a specific context affects attitudes toward market-based transactions in another context, i.e. whether there is a cross-effect of information. The emergence of evidence on the beneficial role of a price mechanism in a morally controversial setting might also change beliefs about the acceptability of such a mechanism in another context. The cross-effect, if any, could also go in the opposite direction; it is possible that thinking about markets in one context increases the "repugnance" for another set of transactions.

Relying on an online survey experiment with more than 5,000 U.S. residents and using a similar experimental design as in ELM (2015a), we found no effect of general information about market efficiency, consistent with morally controversial markets being accepted when they are seen as a solution to a specific problem, rather than because people think that they can solve all problems. We also found some cross-effects of information about a transaction on the acceptance of the other; however, the responses were mediated by the gender and (to a lesser extent) religiosity of the respondent-in particular, women exposed to information about legalizing prostitution reduced their stated support for regulated organ payments. 
The estimated support rates for each condition are illustrated in Fig 2. The baseline support for legalizing organ payments and indoor prostitution (i.e. for subjects who did not read any text) was $67.6 \%$ and $65.3 \%$, respectively. ${ }^{6}$

None of our treatments had a meaningful effect on the support for legalizing indoor prostitution. Reading a text with general considerations about the efficiency properties of market systems reduced support for legalizing prostitution by four percentage points (top-left panel of Fig 2). The text regarding the organ shortage and methods to solve it (including a price mechanism) increased support for indoor prostitution by 7 percentage points (top-right panel).

As for support for organ payments, Fig 2 shows that the market text was associated with a statistically insignificant 10 percentage-point reduction in support for legalized payments to organ donors or their families (bottom-left panel), whereas reading a text about the potential reduction in violence and STDs associated with legalized indoor prostitution reduced support for organ payments by a large and statistically significant 20 percentage points (bottom-right panel). Heterogeneity analysis reveals that the latter effect was largely due by women's dramatic reduction in support for legalizing organ payments after reading the prostitution text (from $69 \%$ to $37 \%$ ). This finding is consistently with what we previously found with respect to the "direct" effect of information about legalizing prostitution on support for this activity for women (ELM, 2015a), as well as with existing literature documenting the deep opposition of women toward a market for sex, plausibly triggered by associations of prostitution with stigmatization, sexual dominance and women's oppression.

Two main insights can be derived from our analyses. First, general information (or additional focus) on the efficiency properties of markets did not affect individual attitudes toward the introduction of markets or price-mediated transactions in such morally controversial cases as organ donation and prostitution. This contrasts with the positive effect of providing contextspecific information and a focus on the effects of markets in particular cases. Moreover, the null effects of general market information (and if any, some directionally negative effects) are inconsistent with an increased focus on markets necessarily relaxing or corrupting the moral constraints in which people believe. On the contrary, for some groups, such as women and religious individuals, it had a negative effect, making them less favorable to the use of markets. Second, we found some evidence of "spillover" effects of information on a morally controversial transaction to another, at least in a case where the two considered activities are somewhat related to the trade of the human body or body parts; however, these spillovers varied according to individual characteristics, such as gender, and other deep beliefs, such as religion.

These results imply that the provision of well-supported information can change attitudes toward the acceptance of morally charged market trades but it has been context-specific, thus potentially leading to implementing, or at least experiment with some market-based solutions to socially pressing issues such as the shortage organs for transplant. Because of the different responses for different activities, and interactions between attitudes, a case-by-case approach

\footnotetext{
${ }^{6}$ The approval rate for organ payments was higher than what we found in our previous studies. This is most likely due to different sampling, and it is not the main focus of the study because we are interested in the difference between the baseline and the support after receiving additional information.
} 
appears to be preferable for both scholars and policymakers in exploring responses to the introduction of such market-based solutions.

\section{Choices Can Change: Repugnance and Economic Development}

Another factor that could affect repugnance is economic development. In Elias at al. (2017) we argue that development can affect attitudes toward (and regulation of) morally contentious transactions through three channels mainly: changes in the efficiency effects of the transaction, changes in the perceived repugnance of a transaction, and changes in the individuals' relative valuation of repugnance and efficiency due to income effects.

The first channel operates through changes in the net benefits of an activity associated with economic development. For example, technological change that makes kidney transplants safer and more effective increases the benefits of transplantation. At the same time, economic development is likely to change the perceived repugnance of a transaction, through modifications in how the activity is performed. Finally, economic development has income effects, that increase the value of normal goods, including the value of life and safety (Viscusi, 2008) and individual rights (Doepke, Tertilt and Voena 2010; Duflo 2012). Increase in individual's willingness to pay for safety would lead to relax regulations of activities that enhance life expectancy. The positive effect on the valuation of individual rights could also promote permissive regulations that favor individuals' autonomy. However, the latter could also lead to severe restrictions on activities that are perceived as coercive or exploitative of marginalized groups in society.

Elias et al. (2017) provide evidence of the heterogeneity in the regulation of morally contentious activities across counties and over time, from 1960 to 2015, for three morally contentious activities: abortion, prostitution and gestational surrogacy, and explore the relationship between a country's economic conditions and how these activities are regulated.

Figure 3a reports the evolution over time of the distribution of abortion regulations across countries, between 1960 and 2015. In 1960, about half of the countries did not have any regulation regarding abortion; by 2015 , a law existed in virtually every country. Of the countries with legislation, about half prohibited abortion (or allowed it only to save the mother's life) in 1960, and less than $20 \%$ allowed pregnancies to be terminated on request or for socioeconomic reasons. In 2015 , by contrast, abortion was illegal in only a quarter of the countries, whereas about $40 \%$ of the countries allowed it upon request or for socio-economic reasons.

In 1960 only about $10 \%$ of countries had legislation regulating prostitution (Figure 3b), against almost $60 \%$ in 2015 . Among countries with legislation, the proportions of countries prohibiting or allowing prostitution is similar at the two ends of the time period that we consider, with about $60 \%$ having formal legislation prohibiting the exchange of sex for money, about $30 \%$ allowing it but prohibiting brothels and pimping, and about $10 \%$ of the countries allowing also the exercise of brothels and pimping. 
Figure $3 c$ shows that legislation on surrogacy was first adopted in some countries only in the mid-1980s; in fact, non-traditional forms of gestational surrogacy have become possible only recently, thanks to innovations such as in-vitro fertilization. According to our data, in 2015, legislation was present in 35 countries. Of these, 15 currently prohibit any kind of surrogacy, allow only altruistic surrogacy, and 10 allow both altruistic and commercial surrogacy.

The paper found that higher income is associated with more permissive legislation on abortion, and, to a more limited extent, prostitution. It also found that the relationship between income and the legislation on these activities is affected by historical, cultural and political factors, notably religion and women's political and economic rights. As for gestational surrogacy, descriptive evidence suggests that higher income countries might be more likely to allow altruistic surrogacy but are not more likely to permit commercial surrogacy.

These patterns are somewhat consistent with the evidence that cost-benefit considerations affect attitudes towards repugnant transaction discussed in section 3 .

\section{Conclusions}

As highlighted by market designer (and Nobel laureate) Alvin Roth, "we need to understand better and engage more with the phenomenon of 'repugnant transactions', which often serves as an important constraint on markets and market design." The prohibition on payments to kidney donors is one important example of this phenomenon. Our research suggests that individual choices based on repugnance considerations respond in a predictable way to efficiency, and to information and evidence on the likely effects of introducing payments in morally contested contexts.

Supplying evidence and promoting studies on a number of sensitive topics might therefore lead to greater awareness and improved policy design based on the actual preferences of a population. In the case of introducing regulated payments for organ donors and their families in particular, the evidence is particularly strong that informing society about the potential benefits of economic incentives does impact the acceptability of this transaction.

There is no consensus as of whether preferences of the public should matter for public policy. For example, Gillespie (2017), mentioned above, claims that "questions of human organ procurement strategies, like many normative questions, are about the ethics and legality of the matter in question." Others have been even more explicit that "lay" people's preferences on these issues should not matter: Segev and Entry (2010) write: "But even if we believe that today more than half of the US public supports payment for organ donation, does this change anything for those seeking to establish a national organ market, or those fighting against it? Should we devote resources to investigating the nuances of public attitudes toward these markets? Probably not, for two major reasons. (...) nothing else is relevant until physicians support organ sales..." (). According to Brennan and Jaworksi (2015), on the other hand, "certain ways of buying and selling things might be wrong ... Perhaps buying a kidney from an uninformed, reckless seller is wrong, but you could instead buy one from an informed, rational seller." Our evidence on the evolution of regulations of controversial activities across countries and its association with economic development is consistent with the fact that preferences of the public do influence policy. 
Because individual preferences appear to depend on expected efficiency in addition to ethical considerations, pilot trials testing the outcomes of different arrangements may enhance the ability of a population to determine the preferred organ procurement and allocation system. There are other markets in which some transactions are considered repugnant, including the market for sex (prostitution), reproduction (surrogacy), drugs (narcotics), in which the lack of knowledge and information could be one of the main causes of the restrictive regulations that we currently observe. For market design in general, the evidence we presented in this paper supports the use of experiments and pilot trials to assess the most effective way of organizing trades, taking into account ethical considerations. Repugnance cannot be neglected in policy design, but accurate information on the impact of the regulation is also important for individual and societal choice. 


\section{Figures and tables}

Figure 1. Repugnance toward Different Organ Procurement and Allocation Systems, and Predicted Number of Transplants

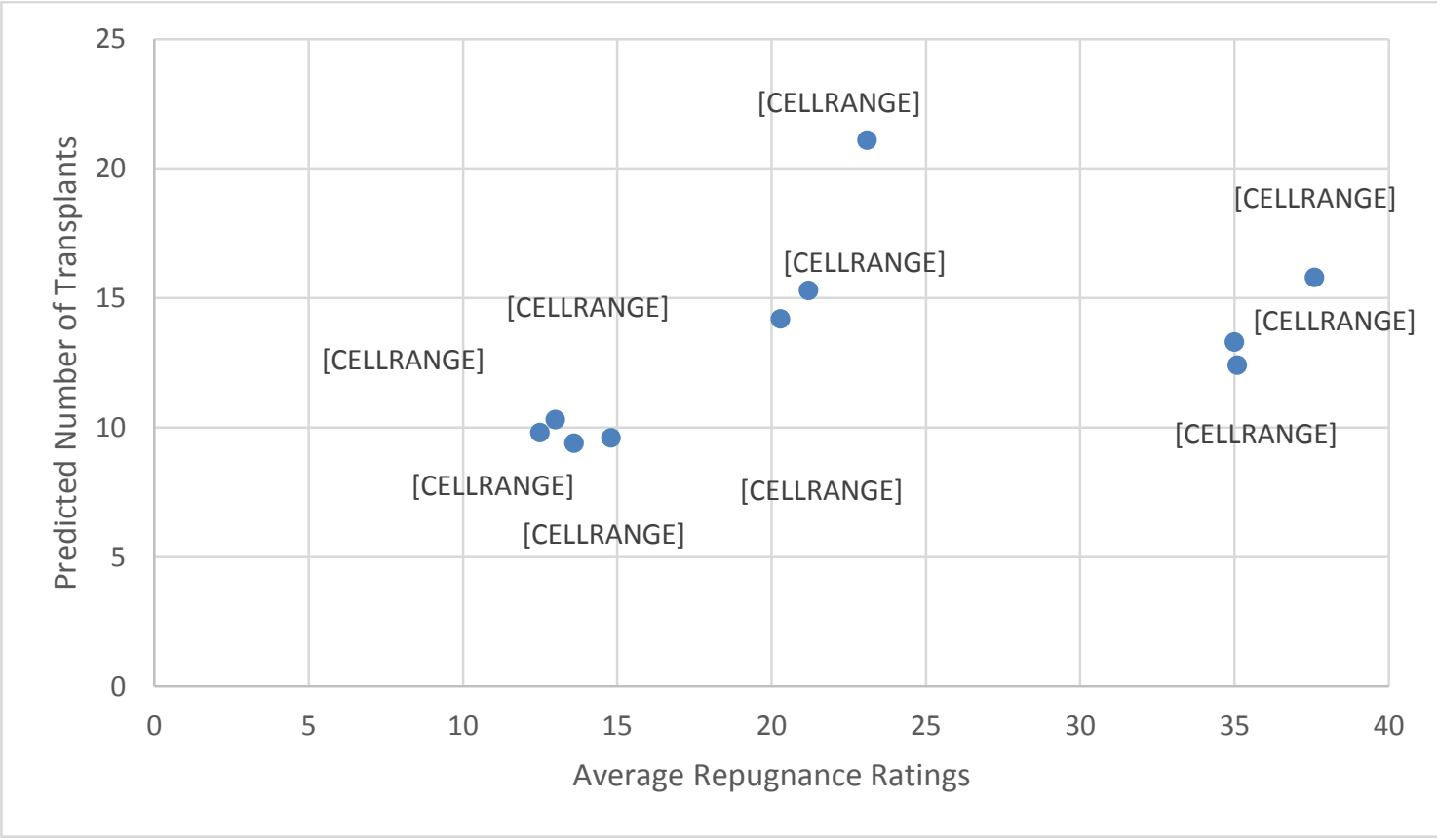


Figure 2:

prostitution
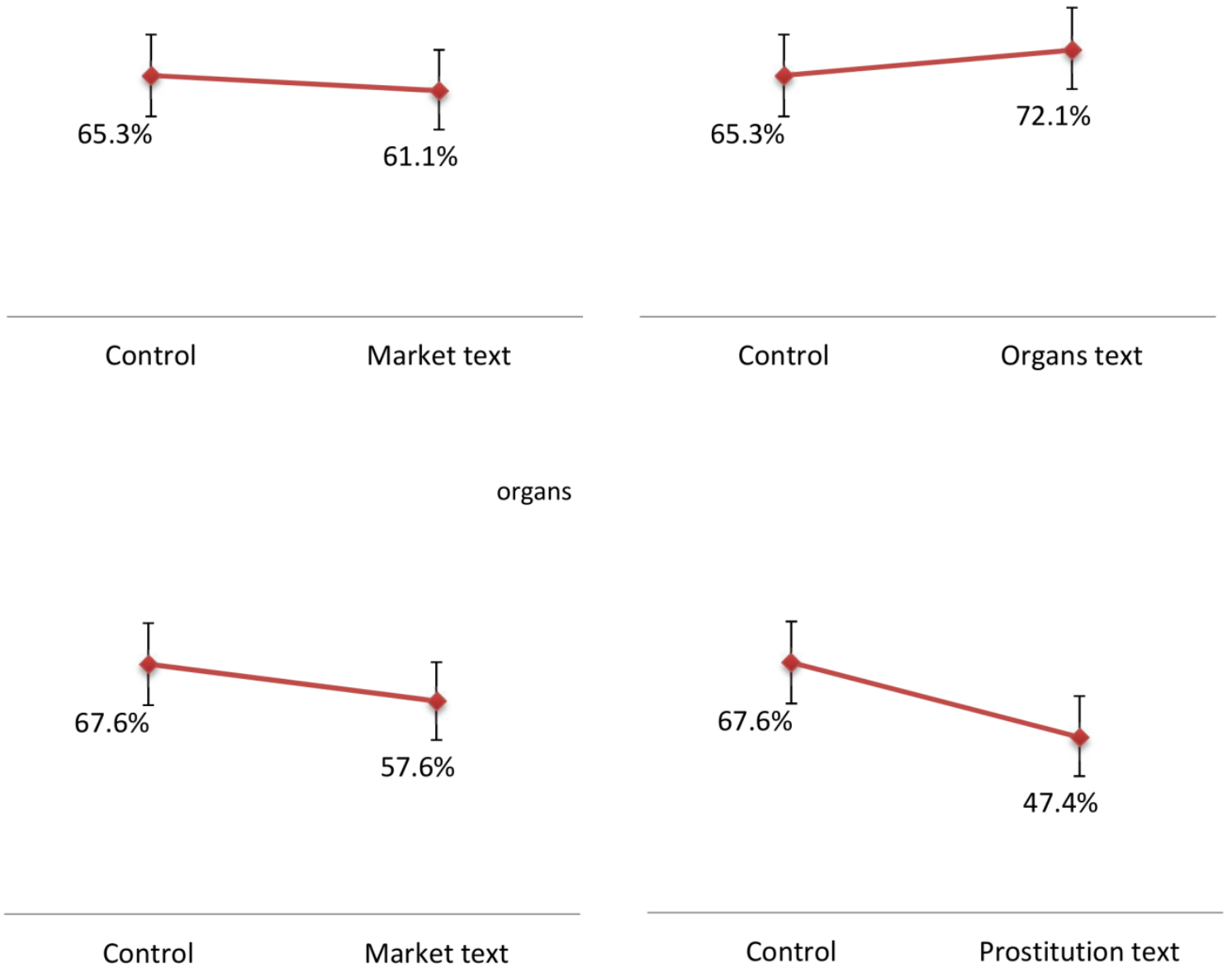

Note: Figure 2 is reprinted from ELM (2015a) and ELM (2015b). 


\section{Figure 3:}

\section{3a. Abortion}

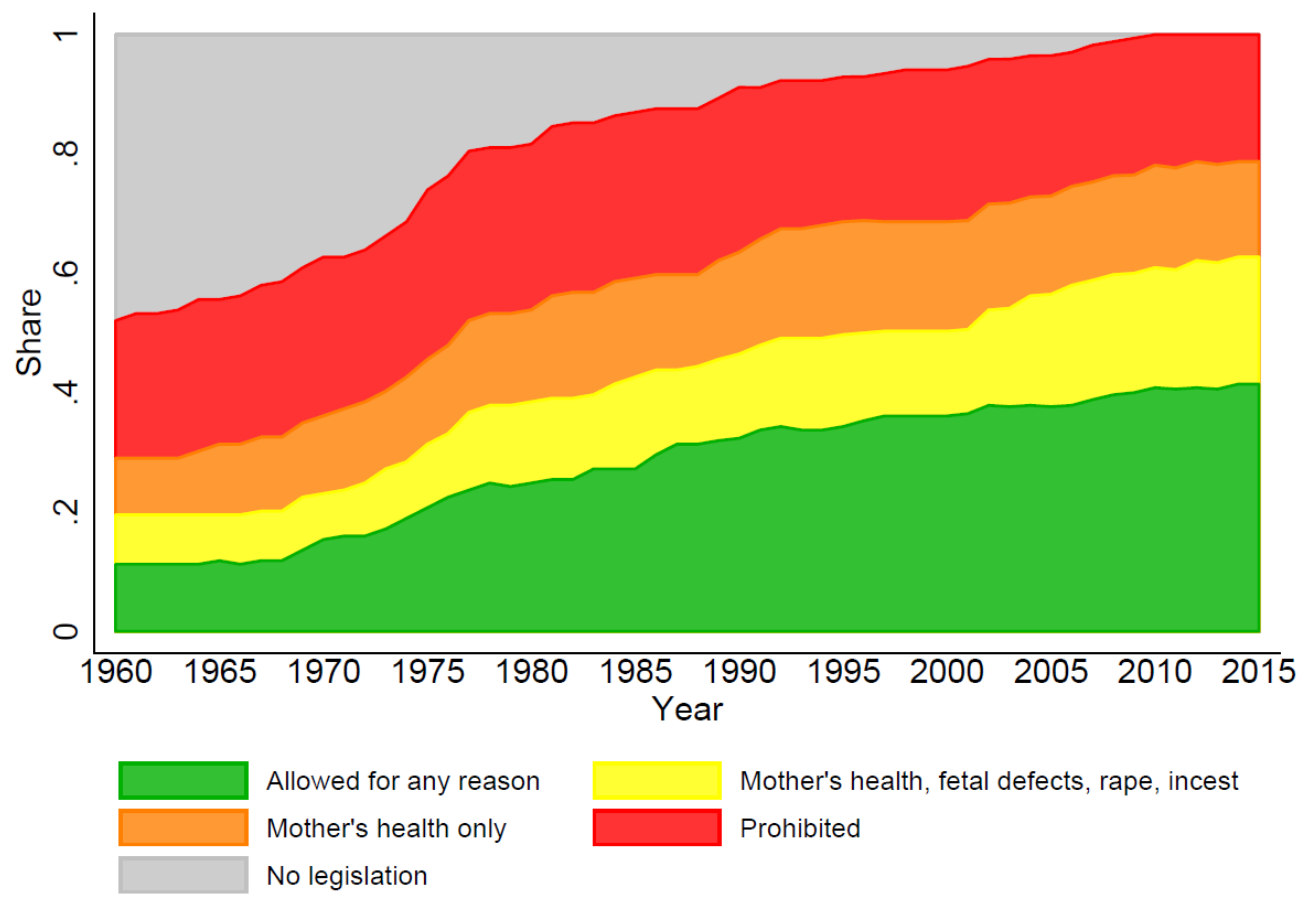

\section{3b. Prostitution}

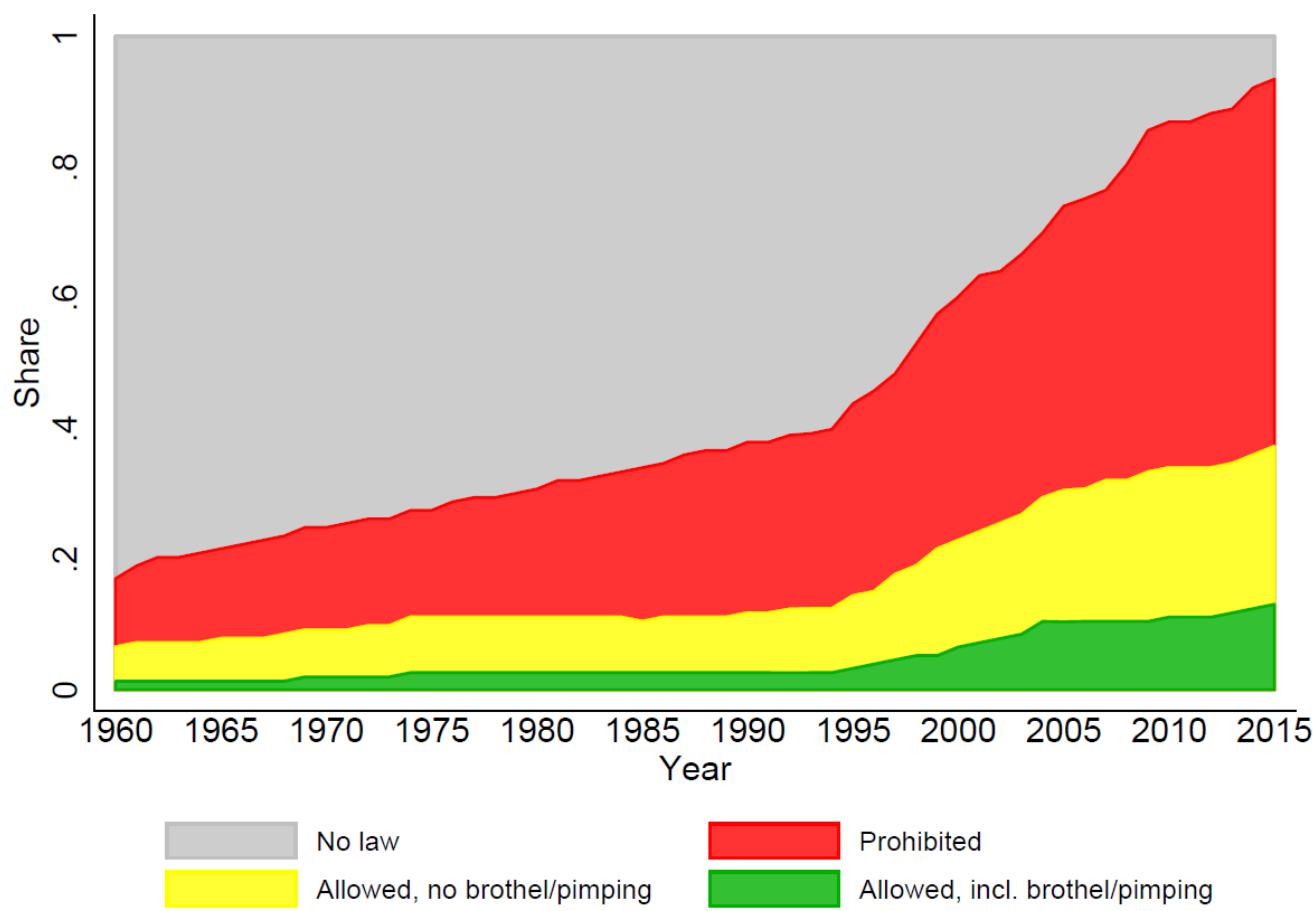




\section{3c. Surrogacy}

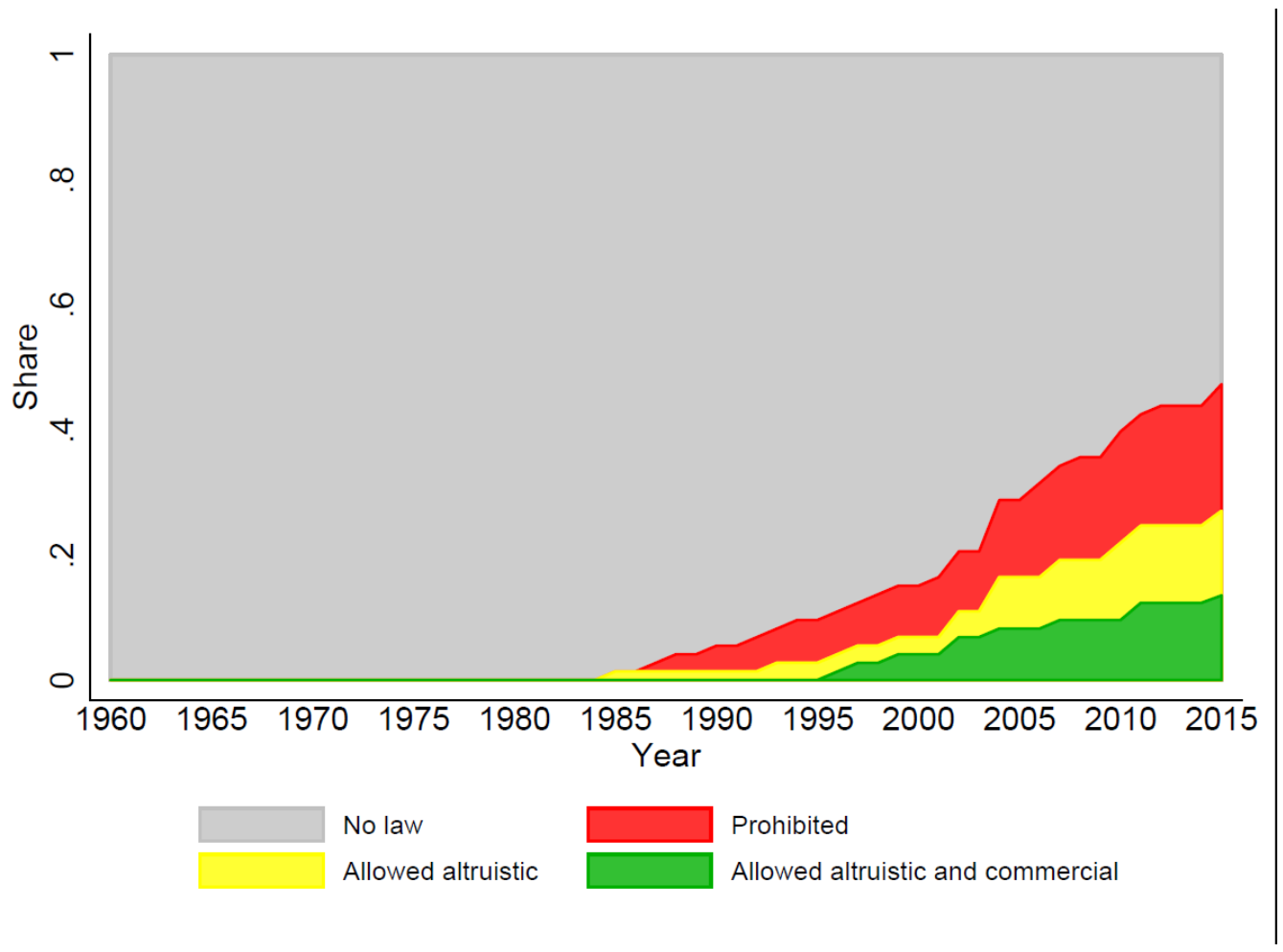

Note: Figures $3 a, 3 b$ and $3 c$ are reprinted from Elias, Lacetera, Macis and Salardi (2017). 


\section{References}

Beauchamp T, Childress J. Principles of Biomedical Ethics, 7thÂ Edition. New York: Oxford University Press, 2013

Becker, G. S., \& Elias, J. J. (2007). Introducing incentives in the market for live and cadaveric organ donations. The Journal of Economic Perspectives, 21(3), 3-24.

Brennan, Jason and Peter Jaworski. 2015. "What are the Limits to Markets? If You May Do It for Free, You May Do It for Money," Cato Unbound, November.

Buhrmester, Michael, Tracy Kwang, and Samuel D. Gosling. "Amazon's Mechanical Turk a new source of inexpensive, yet high-quality, data?." Perspectives on psychological science 6.1 (2011): 3-5.

Delmonico, F. et al. (2002). Ethical incentives-not payment-for organ donation. New England Journal of Medicine, 346(25).

Elias, Julio J. 2017. The role of repugnance in the development of markets: The case of the market for kidneys for transplants. In Costa-Font, J. and Macis, M. (Eds.), Social Economics, Cambridge: MIT Press.

Elias, Julio J., Nicola Lacetera, and Mario Macis. 2015a. Sacred Values? The Effect of Information on Attitudes toward Payments for Human Organs. P\&P of the American Economic Review, 105(5): 361-65.

Elias, Julio J., Nicola Lacetera, and Mario Macis. 2015b. Markets and Morals: An Experimental Survey Study. PloS one 10 (6), e0127069

Elias, Julio J., Nicola Lacetera, and Mario Macis. 2016a. Efficiency-Morality Trade-Offs in Repugnant Transactions: A Choice Experiment. NBER Working Paper No. 22632.

Elias, Julio J., Nicola Lacetera, and Mario Macis. 2016b. Understanding moral repugnance: The case of the US market for kidney transplantation. Vox, CEPR's Policy Portal.

Elias, Julio J., Nicola Lacetera, Mario Macis, and Paola Salardi. 2017. Economic Development and the Regulation of Morally Contentious Activities. NBER Working Paper No. 23214.

Gibson, R., Tanner, C., \& Wagner, A. F. (2013). Preferences for truthfulness: Heterogeneity among and within individuals. American Economic Review, 103, 532-548.

Gillespie, R. 2017. "What Money Cannot Buy and What Money Ought Not Buy: Dignity, Motives, and Markets in Human Organ Procurement Debates," Journall of Medical Humanities. Jan 06.

Gneezy, U. 2005. "Deception: the role of consequences," American Economic Review 9, 384394.

Guiso, Luigi, Paola Sapienza, and Luigi Zingales. 2006. "Does Culture Affect Economic Outcomes?" Journal of Economic Perspectives, 20(2): 23-48. 
Held, P. J., McCormick, F., Ojo, A., \& Roberts, J. P. (2016). A Cost-Benefit Analysis of Government Compensation of Kidney Donors. American Journal of Transplantation, 16(3) 877885.

Kuziemko, I., Norton, M. I., Saez, E. and Stantcheva, S. (2015). How Elastic Are Preferences for Redistribution? Evidence from Randomized Survey Experiments. American Economic Review, 105(4), 1478-1508.

Lacetera, N. 2017 "Incentives and Ethics in the Economics of Body Parts." Osgoode Hall Law Journal 54(2): 397-417.

Leider, S., \& Roth, A. E. (2010). Kidneys for sale: Who disapproves, and why? American Journal of Transplantation, 10(5), 1221-1227.

Mason, Winter, and Siddharth Suri. "Conducting behavioral research on Amazon's Mechanical Turk." Behavior research methods 44, no. 1 (2012): 1-23.

Radin, Margaret Jane. "Market-Inalienability." Harvard Law Review, vol. 100, no. 8, 1987, pp. 1849-1937.

Roth, A. E. (2007). Repugnance as a Constraint on Markets. Journal of Economic Perspectives, 21(3), 37-58.

Sandel M. 2012. What Money Can't Buy: The Moral Limits of Markets, Farrar, Straus and Giroux.

Segev, D. L. and S. E. Entry. "Kidneys for sale: Whose attitudes matter?," American Journal of Transplantation, 2010

Shweder, R.A., Much, N.C., Mahapatra, M., \& Park, L. (1997). The "Big Three" of Morality (Autonomy, Community, Divinity) and the "Big Three" Explanations of Suffering. In A. Brandt \& P. Rozin (Eds.) Morality and Health (pp. 119-169). New York: Routledge. 